\title{
Missed opportunities for prevention of vertical HIV transmission in Canada, 1997-2016: a surveillance study
}

\author{
Ari Bitnun MD MSc, Terry Lee PhD, Jason Brophy MD MSc, Lindy M. Samson MD MSc, \\ Fatima Kakkar MD MPH, Wendy Vaudry MD, Ben Tan MD, Deborah M. Money MD, Joel Singer PhD, \\ Laura J. Sauvé MD MPH, Ariane Alimenti MD; for the Canadian Perinatal HIV Surveillance Program
}

\section{Abstract}

Background: Vertical HIV transmission has declined in Canada, but missed opportunities for prevention continue to occur. We sought to determine the adequacy, and changes over time in adequacy, of uptake of maternal and neonatal antiretroviral therapy for the prevention of vertical HIV transmission, and to determine the vertical transmission rate over time and according to adequacy of antenatal antiretroviral therapy during the combination antiretroviral therapy era in Canada.

Methods: The Canadian Perinatal HIV Surveillance Program collects data annually through retrospective chart review concerning HIV-infected women and their infants. We determined receipt of adequate antiretroviral treatment (antenatal combination antiretroviral treatment for $\geq 4 \mathrm{wk}$, intrapartum intravenous zidovudine treatment and 4-6 wk of infant oral zidovudine treatment) and predictors of inadequate antenatal combination antiretroviral therapy (none or < 4 wk) in Canada in 1997-2016.

Results: We identified 3785 mother-infant pairs. Uptake of 4 weeks or more of antenatal combination antiretroviral therapy increased over time across all provinces/territories and regardless of maternal race/ethnicity or risk category $(p<0.001)$. During 2011-2016, 92 women (6.5\%) received no or less than 4 weeks of antenatal combination antiretroviral therapy, 146 women (10.7\%) received no intrapartum zidovudine treatment, and 43 infants (3.1\%) received less than 4 weeks of zidovudine treatment. In multivariate analysis restricted to 2011-2016, higher uptake of adequate antenatal combination antiretroviral therapy was seen among black women than among Indigenous (odds ratio [OR] 2.99, 95\% confidence interval [Cl] 1.23-7.26) or white (OR 1.87, 95\% $\mathrm{Cl} 0.99-1.27)$ women and in British Columbia/Yukon Territory than in Alberta (OR 3.31, 95\% Cl 1.06-10.32), Ontario (OR 3.16, 95\% Cl 1.08-9.26) or Quebec (OR 3.44, 95\% Cl 1.09-10.84). Among the 14 vertical HIV transmission events during 2011-2016 (vertical transmission rate $1.0 \%$ ), maternal HIV infection was diagnosed before the onset of labour in 5 cases, and only 2 women received adequate antenatal combination antiretroviral therapy.

Interpretation: Efforts to improve timely access to care, HIV screening and treatment for all women, combined with enhanced resources targeting populations at increased risk for HIV infection, will be needed if vertical HIV transmission is to be eliminated in Canada.

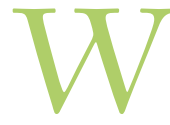

ith the provision of combination antiretroviral therapy to women during pregnancy, intravenous zidovudine treatment during labour, 4-6 weeks of oral zidovudine treatment in the newborn and exclusive formula feeding, the risk of vertical HIV transmission has declined to $0.27 \%-2.9 \%$ in developed countries. ${ }^{1-6}$ Canadian data for 1990-2010 showed a vertical HIV transmission rate of $16.4 \%$ when women received no antenatal combination antiretroviral therapy, $1.6 \%$ when they were prescribed antenatal mono or dual nucleoside-analogue therapy, and $1.0 \%$ when they were prescribed antenatal combination antiretroviral therapy. ${ }^{4}$

Missed opportunities for the prevention of vertical HIV transmission continue to occur in developed countries. ${ }^{7,8}$ For example, among women enrolled in the European Collabora- tive Study, between 2000 and 2009, 9\% of pregnant women received less than 2 weeks of antenatal combination antiretroviral therapy or no such therapy, despite the fact that HIV infection had been diagnosed in $50 \%$ of these women before conception. ${ }^{7}$ Risk factors that have been associated with ongoing vertical HIV transmission include absent or inadequate antenatal care, late maternal diagnosis, injection drug use, lack

\section{Competing interests: None declared.}

This article has been peer reviewed.

Correspondence to: Ari Bitnun, ari.bitnun@sickkids.ca

CMAJ Open 2018. DOI:10.9778/cmajo.20180016 
of antiretroviral treatment during pregnancy, labour and delivery, preterm delivery and incomplete avoidance of breast-feeding. ${ }^{7-11}$

The objectives of the present study were to determine the adequacy, and changes over time in adequacy, of uptake of antenatal and intrapartum maternal and postpartum neonatal antiretroviral therapy for the prevention of vertical HIV transmission, and to determine the vertical transmission rate over time and according to adequacy of antenatal antiretroviral therapy during the combination antiretroviral therapy era (1997-2016) in Canada. We further sought to evaluate recent trends by investigating predictors of inadequate uptake of antenatal antiretroviral therapy for the period 2011-2016.

\section{Methods}

\section{Setting, design and participants}

The Canadian Perinatal HIV Surveillance Program (CPHSP) collects data from $22 \mathrm{HIV}$ referral health centres and health departments from across Canada that include representation from all provinces and territories. Nineteen of the 22 centres are obstetric and/or pediatric care centres located in the 10 provinces; the remaining 3 are public health units of each of the 3 territories. The program was initiated in 1990 under the auspices of the Canadian Pediatric \& Perinatal HIV/AIDS Research Group and is supported by the Public Health Agency of Canada. Data management and analysis are conducted at the CIHR Canadian HIV Trials Network data centre in Vancouver.

The CPHSP methodology has been previously described. ${ }^{4}$ Data are collected annually through retrospective chart review and, since 2008, are submitted electronically via a secure Web-based Oracle database. Maternal data include country of birth, risk category for HIV acquisition, date of HIV diagnosis, self-reported race/ethnicity (according to national surveillance definitions), viral load, antenatal antiretroviral regimen(s) and intrapartum receipt of zidovudine. Infant data include place of birth, mode of delivery, gestational age at birth, birth weight, sex, antiretroviral prophylaxis and HIV status. The CPHSP began collecting maternal viral load and infant birth weight systematically in 2008. Infant HIV status is reported as confirmed if $\mathrm{HIV}$ is detected in 2 separately timed virologic assays before 18-24 months of age or by HIV serologic testing after that age. HIV-negative status is defined as negative results of 2 or more separately timed virologic assays performed at 1 month of age or later during the first 18 months of life or by a negative result of HIV serologic testing after that age. Indeterminate status is reserved for cases not finalized by these criteria.

To be eligible for inclusion in this study, children had to have been born in Canada between Jan. 1, 1997, and Dec. 31, 2016, to a mother with confirmed HIV infection. Inadequate antiretroviral therapy was defined as less than 4 weeks of antenatal combination antiretroviral therapy, no intrapartum intravenous zidovudine treatment ${ }^{12,13}$ or less than 4 weeks of oral zidovudine treatment in the infant. ${ }^{12,13}$

\section{Statistical analysis}

We summarized demographic characteristics using percentages, means with standard deviations (SDs) or medians with ranges as appropriate. We used the $\chi^{2}$ test or Fisher exact test as appropriate to compare maternal risk category, maternal race/ethnicity, geographic region of infant birth, timing of maternal diagnosis and antiretroviral therapy rates across time periods. We assessed time trends of rates using logistic regression with child birth year being modelled as a continuous variable. We used logistic regression modelling to examine the relation between uptake of antenatal combination antiretroviral therapy and potential explanatory variables, including demographic and clinical characteristics and child year of birth (mother-infant pairs with missing documentation of receipt of antenatal combination antiretroviral therapy were excluded). We restricted the analysis of predictors of inadequate uptake of antenatal combination antiretroviral therapy to the period 2011-2016 as this was deemed most relevant to the current situation. For detailed review of vertical HIV transmission events, we included all cases regardless of data completeness. Analyses were conducted with the use of SAS 9.4 (SAS Institute).

\section{Ethics approval}

Ethics approval for the surveillance was obtained from the research ethics boards of all participating centres.

\section{Results}

Between 1997 and 2016, 3785 infants were born in Canada to mothers with documented HIV infection. Baseline maternal characteristics and delivery-related factors are shown in Table 1. For 60 mother-infant pairs (1.6\%) (27 in 19972010, 33 in 2011-2016), infant HIV status was indeterminate, with explanation documented in 18 cases (death [10 cases], moved out of Canada [8]); the remaining 42 pairs were lost to follow-up. All deaths occurred within 5 months of birth, and none were attributed to HIV infection. The vertical HIV transmission rate for the remaining 3725 mother-infant pairs was 3.4\% (125/3725). During 2011-2016, the vertical transmission rate was $1.0 \%(14 / 1385)$. The vertical transmission rate for the full study period was $28.9 \%$ in the absence of antenatal combination antiretroviral therapy, $4.3 \%$ with less than 4 weeks of such therapy and $0.2 \%$ with 4 weeks or more of such therapy.

Information on antiretroviral therapy uptake was complete for 3724 (98.4\%) of the 3785 mother-infant pairs; information was missing on antenatal combination antiretroviral therapy in 21 cases, intrapartum intravenous zidovudine treatment in 50 cases and infant zidovudine treatment in 12 cases. Inadequate antiretroviral therapy was noted in 1112 $(29.9 \%)$ of the 3724 mother-infant pairs, including 804 women $(21.6 \%)$ who received no antenatal combination antiretroviral therapy $(359[9.6 \%])$ or less than 4 weeks of such therapy (445 [11.9\%]), 534 women $(14.3 \%)$ who received no intrapartum intravenous zidovudine treatment and 237 infants $(6.4 \%)$ who received less than 4 weeks of oral 
Table 1 (part 1 of 2): Maternal and delivery-related characteristics of HIV-infected women and their infants, Canada, 1997-2016

\begin{tabular}{|c|c|}
\hline Characteristic & $\begin{array}{c}\text { No. }(\%) \text { of } \\
\text { mother-infant } \\
\text { pairs }{ }^{*}\end{array}$ \\
\hline \multicolumn{2}{|l|}{ Women } \\
\hline \multicolumn{2}{|l|}{ Risk category $(n=3459)$} \\
\hline Heterosexual & 2555 (73.9) \\
\hline Injection drug use $†$ & $788(22.8)$ \\
\hline Perinatal $\ddagger$ & $44(1.3)$ \\
\hline Other & $72(2.1)$ \\
\hline \multicolumn{2}{|l|}{ Race/ethnicity $(n=3723) \S$} \\
\hline Black & $1868(50.2)$ \\
\hline White & $843(22.6)$ \\
\hline Indigenous & $778(20.9)$ \\
\hline Other & $234(6.3)$ \\
\hline \multicolumn{2}{|l|}{ Timing of diagnosis $(n=3317) \emptyset$} \\
\hline Before conception & $2593(78.2)$ \\
\hline First trimester & $197(5.9)$ \\
\hline Second trimester & $278(8.4)$ \\
\hline Third trimester & $103(3.1)$ \\
\hline At delivery & $53(1.6)$ \\
\hline After delivery & $93(2.8)$ \\
\hline \multicolumn{2}{|l|}{$\begin{array}{l}\text { Duration of antenatal combination } \\
\text { antiretroviral therapy, wk }(n=3764)\end{array}$} \\
\hline$\geq 4$ & $2960(78.6)$ \\
\hline$<4$ & $445(11.8)$ \\
\hline None & $359(9.5)$ \\
\hline \multicolumn{2}{|l|}{$\begin{array}{l}\text { Viral load nearest delivery, copies } / \mathrm{mL} \\
(n=2467)^{\star *}\end{array}$} \\
\hline$<50$ & 2031 (82.3) \\
\hline 50-999 & $270(10.9)$ \\
\hline$\geq 1000$ & $166(6.7)$ \\
\hline \multicolumn{2}{|l|}{ Mode of delivery $(n=3680)$} \\
\hline Vaginal & $2235(60.7)$ \\
\hline Elective cesarean birth & $961(26.1)$ \\
\hline Emergency cesarean birth & $484(13.2)$ \\
\hline \multicolumn{2}{|l|}{ Infants } \\
\hline $\begin{array}{l}\text { Gestational age at birth, mean } \pm \text { SD; wk } \\
(n=3394)\end{array}$ & $38.2 \pm 2.41$ \\
\hline \multicolumn{2}{|l|}{ Gestational age at birth, wk $(n=3394)$} \\
\hline$\geq 37$ & $2825(83.2)$ \\
\hline $34-36$ & $396(11.7)$ \\
\hline$<34$ & $173(5.1)$ \\
\hline Birth weight, mean \pm SD; kg $(n=3072)$ & $3.04 \pm 0.65$ \\
\hline Male sex $(n=3785)$ & 1944 (51.4) \\
\hline
\end{tabular}

Table 1 (part 2 of 2): Maternal and delivery-related characteristics of HIV-infected women and their infants, Canada, 1997-2016

\begin{tabular}{|c|c|}
\hline Characteristic & $\begin{array}{c}\text { No. }(\%) \text { of } \\
\text { mother-infant } \\
\text { pairs }\end{array}$ \\
\hline \multicolumn{2}{|l|}{ Province/territory of birth $(n=3785)$} \\
\hline Ontario & 1294 (34.2) \\
\hline Quebec & $859(22.7)$ \\
\hline Alberta & $575(15.2)$ \\
\hline British Columbia/Yukon Territory†† & $493(13.0)$ \\
\hline Saskatchewan & $288(7.6)$ \\
\hline Manitoba & $247(6.5)$ \\
\hline Atlantic provinces & $29(0.8)$ \\
\hline \multicolumn{2}{|c|}{$\begin{array}{l}\text { Note: SD = standard deviation. } \\
{ }^{*} \text { Except where noted otherwise. } \\
\text { †Most prevalent as a maternal risk category in Saskatchewan }(76.2 \%) \text {, British } \\
\text { Columbia }(41.1 \%) \text { and Manitoba ( } 34.1 \%) \text {. } \\
\text { †HIV infection acquired through vertical transmission. } \\
\text { §Black race/ethnicity predominated in Quebec }(68.9 \%) \text {, Ontario }(65.4 \%) \text { and } \\
\text { Alberta ( } 45.0 \%) \text {; Indigenous race/ethnicity predominated in Saskatchewan } \\
(87.5 \%) \text { and Manitoba ( } 59.9 \%) \text {. } \\
\text { Iln } 416 \text { cases, diagnosis was before the onset of labour, but the precise timing } \\
\text { was unknown. } \\
{ }^{* *} \text { Collected consistently since } 2008 \text {. } \\
\text { ††There were fewer than } 5 \text { cases from the Yukon Territory. }\end{array}$} \\
\hline
\end{tabular}

zidovudine treatment. The proportion of women who received 4 weeks or more of antenatal combination antiretroviral therapy increased significantly over time in all regions regardless of maternal risk category or race/ethnicity $(p<0.001)$ (Figure 1). Rates of receipt of intrapartum intravenous zidovudine treatment (odds ratio [OR] per calendar year $1.05,95 \%$ confidence interval [CI $1.03-1.07$ ) and of 4 weeks or more of neonatal zidovudine treatment (OR per calendar year $1.13,95 \%$ CI 1.10-1.16) also increased significantly over time. Nevertheless, during 2011-2016, 92 women (6.6\%) received no $(51$ women [3.7\%]) or inadequate $(<4 \mathrm{wk}$, 41 women $[3.0 \%]$ ) antenatal combination antiretroviral therapy, 146 women $(10.5 \%)$ received no intrapartum intravenous zidovudine treatment, and 43 infants $(3.1 \%)$ received less than 4 weeks of oral zidovudine treatment (Table 2). Of the 1302 women in whom HIV infection was diagnosed before the third trimester during this period, 32 (2.4\%) received less than 4 weeks of antenatal combination antiretroviral therapy, and $24(1.8 \%)$ received no antenatal combination antiretroviral therapy.

The timing of diagnosis of maternal HIV infection, available for 3317 mother-infant pairs (87.6\%), was before the third trimester in 3068 women (92.5\%). The rate of diagnosis before the third trimeter increased from $67.4 \%$ in 1997 to $94.4 \%$ in 2016 (OR per calendar year 1.16, 95\% CI $1.13-$ 1.19). For 2011-2016 $(n=1355)$, the rate of diagnosis before the third trimester was lower among Indigenous women $(92.9 \%)$ than among white women $(97.2 \%, p=0.02)$ and black women $(97.8 \%, p<0.001)$, and among women with injection drug use as their risk category than among those 


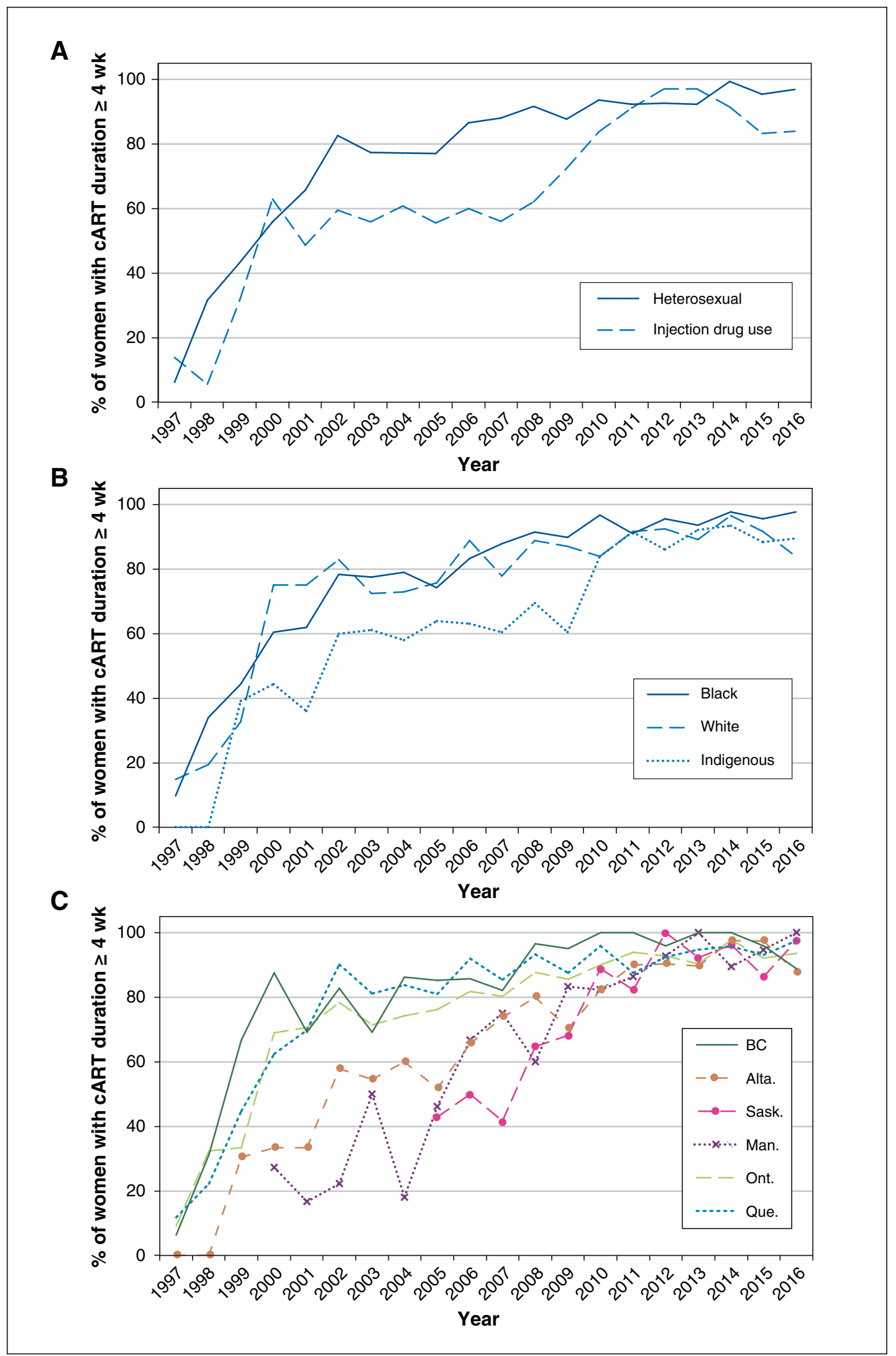

Figure 1: Proportion of women who received antenatal combination antiretroviral therapy (cART) for 4 weeks or more according to (A) risk category, (B) race/ethnicity and (C) geographic region, 1997-2016. For Saskatchewan and Manitoba, data from earlier years are not shown owing to small numbers. 


\begin{tabular}{|c|c|c|c|c|}
\hline \multirow[b]{2}{*}{ Variable } & \multicolumn{3}{|c|}{ Duration of therapy, wk; no. (\%) of women } & \multirow[b]{2}{*}{$p$ value } \\
\hline & $\begin{array}{c}\geq 4 \\
n=1315\end{array}$ & $\begin{array}{c}<4 \\
n=41\end{array}$ & $\begin{array}{l}\text { None } \\
n=51\end{array}$ & \\
\hline \multicolumn{4}{|l|}{ Maternal risk category $\dagger$} & \multirow[t]{2}{*}{0.02} \\
\hline Heterosexual & $899(94.8)$ & $23(2.4)$ & $26(2.7)$ & \\
\hline Injection drug use & $237(89.8)$ & $7(2.7)$ & \multicolumn{2}{|l|}{$20(7.6)$} \\
\hline Perinatal & $29(90.6)$ & $2(6.3)$ & \multicolumn{2}{|l|}{$1(3.1)$} \\
\hline Other & $37(97.4)$ & $0(0.0)$ & \multicolumn{2}{|l|}{$1(2.6)$} \\
\hline \multicolumn{4}{|l|}{ Maternal race/ethnicity $\ddagger$} & \multirow[t]{2}{*}{0.003} \\
\hline Black & $698(95.2)$ & $21(2.9)$ & $14(1.9)$ & \\
\hline Indigenous & $277(90.2)$ & $10(3.3)$ & \multicolumn{2}{|l|}{$20(6.5)$} \\
\hline White & $230(91.6)$ & $6(2.4)$ & \multicolumn{2}{|l|}{$15(6.0)$} \\
\hline Other & $91(95.8)$ & $3(3.2)$ & \multicolumn{2}{|l|}{$1(1.1)$} \\
\hline \multicolumn{4}{|c|}{ Infant province/territory of birth } & \multirow[t]{2}{*}{0.4} \\
\hline Ontario & $474(93.5)$ & $13(2.6)$ & $20(3.9)$ & \\
\hline Quebec & $226(93.8)$ & $6(2.5)$ & \multicolumn{2}{|l|}{$9(3.7)$} \\
\hline Alberta & $209(92.1)$ & $10(4.4)$ & \multicolumn{2}{|l|}{$8(3.5)$} \\
\hline Saskatchewan & $159(92.4)$ & $5(2.9)$ & \multicolumn{2}{|l|}{$8(4.7)$} \\
\hline $\begin{array}{l}\text { British Columbia/ } \\
\text { Yukon Territory }\end{array}$ & $142(96.6)$ & $5(3.4)$ & \multicolumn{2}{|l|}{$0(0.0)$} \\
\hline Manitoba & $100(93.5)$ & $2(1.9)$ & \multicolumn{2}{|l|}{$5(4.7)$} \\
\hline Atlantic provinces & $5(83.3)$ & $0(0.0)$ & \multicolumn{2}{|l|}{$1(16.7)$} \\
\hline \multicolumn{5}{|c|}{ 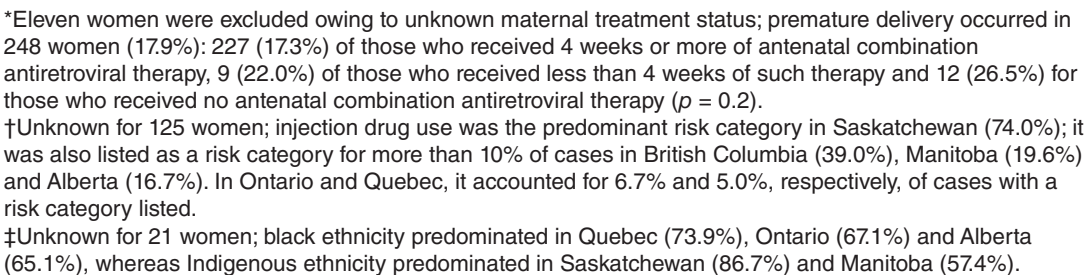 } \\
\hline
\end{tabular}

with heterosexual as their risk category $(92.7 \%$ v. $97.8 \%, p<$ $0.001)$. For both Indigenous and white women, the rate of diagnosis before the third trimester was lower among those with injection drug use as a risk category than among those with heterosexual as a risk category $(91.3 \%$ v. $96.7 \%$ for Indigenous women, $95.1 \%$ v. $98.1 \%$ for white women), but not significantly so. There were no black women with injection drug use noted as a risk category.

Maternal risk category and maternal race but not infant province of birth were significantly associated with adequacy of antenatal combination antiretroviral therapy (Table 2). Among women with heterosexual as a risk category, 86 Indigenous women $(90.5 \%)$ received adequate antenatal combination antiretroviral therapy, compared to 579 black women $(95.5 \%, p=0.05)$ and 152 white women (94.4\%) $(p=0.3)$. Of white women whose risk category was injection drug use, 51 $(85.0 \%)$ received 4 weeks or more of antenatal combination antiretroviral therapy, $1(1.7 \%)$ received less than 4 weeks of such therapy, and $8(13.3 \%)$ received no antenatal combina- tion antiretroviral therapy. The corresponding numbers for Indigenous women were $173(91.1 \%), 5(2.6 \%)$ and 12 $(6.3 \%)$. In Ontario and Quebec, where injection drug use accounted for less than $10.0 \%$ of cases, 24 women $(72.7 \%)$ and 9 women $(75.0 \%)$, respectively, who injected drugs received 4 weeks or more of antenatal combination antiretroviral therapy. In contrast, in Saskatchewan, British Columbia, Manitoba and Alberta, where injection drug use accounted for a higher proportion of cases, $90.9 \%-95.2 \%$ of women who injected drugs received 4 weeks or more of antenatal combination antiretroviral therapy $(p=0.006)$.

The results of univariate and multivariate analysis of potential predictors of adequate antenatal combination antiretroviral therapy uptake for 2011-2016 are depicted in Table 3. In univariate analysis, higher uptake of antenatal combination antiretroviral therapy was observed among black women than among Indigenous and white women, and among women whose risk category was heterosexual than among those whose risk category was injection drug use. In 
Table 3: Predictors of uptake of 4 weeks or more of antenatal combination antiretroviral therapy, 2011-2016

\begin{tabular}{|c|c|c|}
\hline \multirow[b]{2}{*}{ Variable } & \multicolumn{2}{|c|}{ OR $(95 \% \mathrm{Cl})$} \\
\hline & Univariate & Multivariate \\
\hline \multicolumn{3}{|l|}{ Maternal risk category } \\
\hline $\begin{array}{l}\text { Heterosexual } \\
\text { v. injection drug use }\end{array}$ & 2.09 (1.28-3.42) & $1.55(0.77-3.11)$ \\
\hline $\begin{array}{l}\text { Perinatal v. injection } \\
\text { drug use }\end{array}$ & $1.10(0.31-3.86)$ & $0.77(0.21-2.82)$ \\
\hline $\begin{array}{l}\text { Other* v. injection drug } \\
\text { use }\end{array}$ & $4.21(0.56-31.93)$ & $1.61(0.28-9.17)$ \\
\hline \multicolumn{3}{|l|}{$\begin{array}{l}\text { Maternal race/ } \\
\text { ethnicity }\end{array}$} \\
\hline Black v. Indigenous & $2.16(1.30-3.59)$ & $2.99(1.23-7.26)$ \\
\hline White v. Indigenous & $1.19(0.66-2.13)$ & $1.60(0.69-3.70)$ \\
\hline Other v. Indigenous & $2.46(0.85-7.18)$ & $2.12(0.65-6.87)$ \\
\hline Black v. white & $1.82(1.04-3.19)$ & $1.87(0.99-1.27)$ \\
\hline \multicolumn{3}{|l|}{ Province/territory† } \\
\hline $\begin{array}{l}\text { British Columbia/Yukon } \\
\text { Territory v. Alberta }\end{array}$ & $2.45(0.89-6.74)$ & $3.31(1.06-10.32)$ \\
\hline $\begin{array}{l}\text { British Columbia/Yukon } \\
\text { Territory } \\
\text { v. Saskatchewan }\end{array}$ & $2.32(0.81-6.68)$ & $1.33(0.42-4.24)$ \\
\hline $\begin{array}{l}\text { British Columbia/Yukon } \\
\text { Territory v. Manitoba }\end{array}$ & $1.99(0.61-6.44)$ & $2.14(0.63-7.29)$ \\
\hline $\begin{array}{l}\text { British Columbia/Yukon } \\
\text { Territory v. Ontario }\end{array}$ & $1.98(0.76-5.16)$ & $3.16(1.08-9.26)$ \\
\hline $\begin{array}{l}\text { British Columbia/Yukon } \\
\text { Territory v. Quebec }\end{array}$ & $1.88(0.67-5.30)$ & 3.44 (1.09-10.84) \\
\hline $\begin{array}{l}\text { British Columbia/Yukon } \\
\text { Territory v. Atlantic } \\
\text { provinces }\end{array}$ & $5.68(0.56-58.08)$ & $5.48(0.10-314.49)$ \\
\hline Infant birth year & $1.05 \ddagger(0.93-1.19)$ & $1.10 \ddagger(0.96-1.27)$ \\
\hline $\begin{array}{l}\text { Gestational age at } \\
\text { birth }\end{array}$ & $1.07(0.99-1.15)$ & $1.04(0.95-1.14)$ \\
\hline \multicolumn{3}{|c|}{$\begin{array}{l}\text { Note: } \mathrm{Cl}=\text { confidence interval, } \mathrm{OR}=\text { odds ratio. } \\
{ }^{*} \text { Refers to infection acquired via transfusion or other less-common mechanisms. } \\
\text { †All other pairwise comparisons between provinces were nonsignificant. } \\
\text { †Per year increase. }\end{array}$} \\
\hline
\end{tabular}

multivariate analysis, higher uptake of combination antiretroviral therapy among black women than among Indigenous women remained significant, whereas that for black women compared to white women showed borderline significance. Having given birth in British Columbia/Yukon Territory was associated with higher uptake of antenatal combination antiretroviral therapy compared to Alberta, Ontario and Quebec. The impact of risk category was no longer significant in the multivariate model. The infant's gestational age and birth year were not significantly associated with uptake of antenatal combination antiretroviral therapy in either the univariate or multivariate analysis. In a separate multivariate analysis that included a race-risk category interaction term, among women with heterosexual as risk category, uptake of adequate antena- tal combination antiretroviral therapy was significantly better among black women than among Indigenous women (OR 3.94, 95\% CI 1.53-10.14) and was borderline significantly better among white women than among Indigenous women (OR 2.93, 95\% CI 1.00-8.65).

In an analysis stratified by region (British Columbia/Yukon Territory v. Alberta/Saskatchewan/Manitoba v. Ontario/Quebec), the OR for the receipt of 4 weeks or more of antenatal combination antiretroviral therapy for heterosexual v. injection drug use (adjusted for province, birth year, race and gestational age) was 2.75 (95\% CI 1.02-7.39) for Ontario/Quebec, 0.7 (95\% CI 0.26-2.05) for Alberta/Saskatchewan/ Manitoba and 3.7 (95\% CI 0.45-30.68) for British Columbia/ Yukon Territory.

Of the 125 documented vertical HIV transmission events, 111 occurred during 1997-2010, and 14 occurred during 2011-2016 (Figure 2). The timing of maternal diagnosis was available for 122 cases $(97.6 \%)$. In 86 cases $(70.5 \%)$, the women received the diagnosis intra partum $(n=18)$ or post partum $(n=68)$. Among the 36 cases $(29.5 \%)$ in which maternal HIV infection was diagnosed antenatally, combination antiretroviral therapy was not taken during pregnancy in 12 cases, was taken for less than 4 weeks before delivery in 18 cases and was taken for 4 weeks or more before delivery in 5 cases; poor adherence was documented in 3 of the last 5 cases. In 1 case, treatment status was unknown. Salient mother-infant pair characteristics for the 14 cases of vertical HIV transmission that occurred in 2011-2016 are shown in Table 4. Maternal diagnosis was established before the third trimester in only 5 of the 14 cases, and only 2 women received 4 weeks or more of antenatal combination antiretroviral therapy. Seven of the women were black, 6 were Indigenous, and 1 was white. The maternal risk category was heterosexual for 9 women and injection drug use for 5 . Five of the babies were born in Quebec, 5 were born in Saskatchewan, 3 were born in Ontario, and 1 was born in Alberta.

\section{Interpretation}

A major finding of this study was the significant reduction in vertical HIV transmission over time, corresponding with a steady improvement in early diagnosis and uptake of antiretroviral therapy antenatally and during the intrapartum period among HIV-infected pregnant women and during the neonatal period in their children. Nevertheless, as shown by the 14 cases of vertical HIV transmission in 2011-2016 and the observation that $6.5 \%$ of women received no or less than 4 weeks of antenatal combination antiretroviral therapy during the same period, there remains room for improvement in prevention efforts in Canada.

Although increased uptake of antiretroviral therapy was observed across all regions and irrespective of maternal race or risk category, our findings suggest that certain populations in Canada continue to have lower rates of timely diagnosis and uptake of antenatal combination antiretroviral therapy. Injection drug use was associated with late maternal diagnosis and, in Ontario and Quebec (where injection drug 


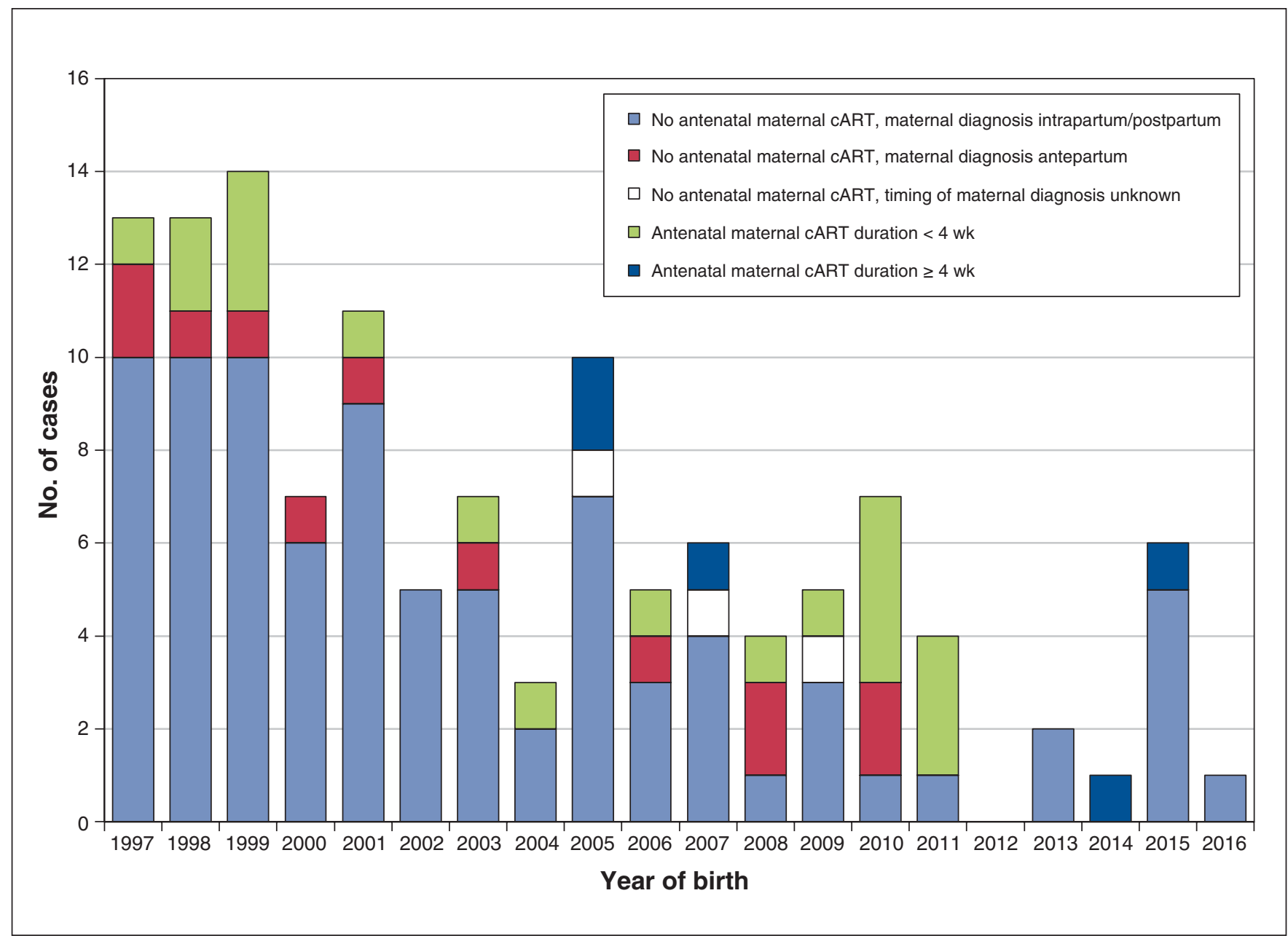

Figure 2: Perinatal infections by infant birth year and antenatal maternal combination antiretroviral therapy (cART). One case of vertical transmission is not shown as maternal cART status was unknown.

use was relatively uncommon as a risk category), with a lower rate of uptake of adequate antenatal combination antiretroviral therapy. The importance of substance abuse as a predictor of late diagnosis, suboptimal antiretroviral therapy and vertical HIV transmission was also shown by several studies from the United States and Europe. ${ }^{3,7,9,14-16}$ The observed lower uptake of antenatal combination antiretroviral therapy in the adjusted analysis for Ontario and Quebec compared to British Columbia/Yukon Territory may reflect, in part, the low uptake of such therapy among women who injected drugs in Ontario and Quebec. In this regard, it is noteworthy that the uptake of antenatal combination antiretroviral therapy was relatively uniform across maternal risk categories for all provinces except Ontario and Quebec. Potential explanations for the lower uptake of antenatal combination antiretroviral therapy among Indigenous women than among black and white women cannot be determined from our data, but the lower uptake likely reflects differences in access to care. ${ }^{17}$

In the French Perinatal Cohort study, no vertical HIV transmission events were observed among the 2651 women who started combination antiretroviral therapy before con- ception and had an undetectable viral load at delivery. ${ }^{5}$ This finding supports the possibility that, with effective interventions, vertical HIV transmission can be eliminated. However, achieving such an outcome in Canada will require concerted commitment and effort given that over two-thirds of vertical HIV transmission events in our cohort occurred in motherinfant pairs in which the woman received the diagnosis after delivery and that adequate combination antiretroviral therapy was taken before delivery in only $14 \%(5 / 36)$ of cases diagnosed antenatally. Enhanced efforts aimed at engaging all women in care and screening them for HIV infection, preferably before conception or as early in pregnancy as possible, followed by prompt initiation of combination antiretroviral therapy will be required. ${ }^{5,14}$ Treating each vertical HIV transmission event as a sentinel health event, whereby system failures are identified and corrected, was associated with a reduction in the vertical transmission rate from $4.3 \%$ to $0 \%$ in Philadelphia ${ }^{18}$ and could potentially be helpful in Canada. Applying such a strategy would require adequate resources for public health, close collaboration between public health and front-line health care providers and, perhaps most important, strong community engagement. 


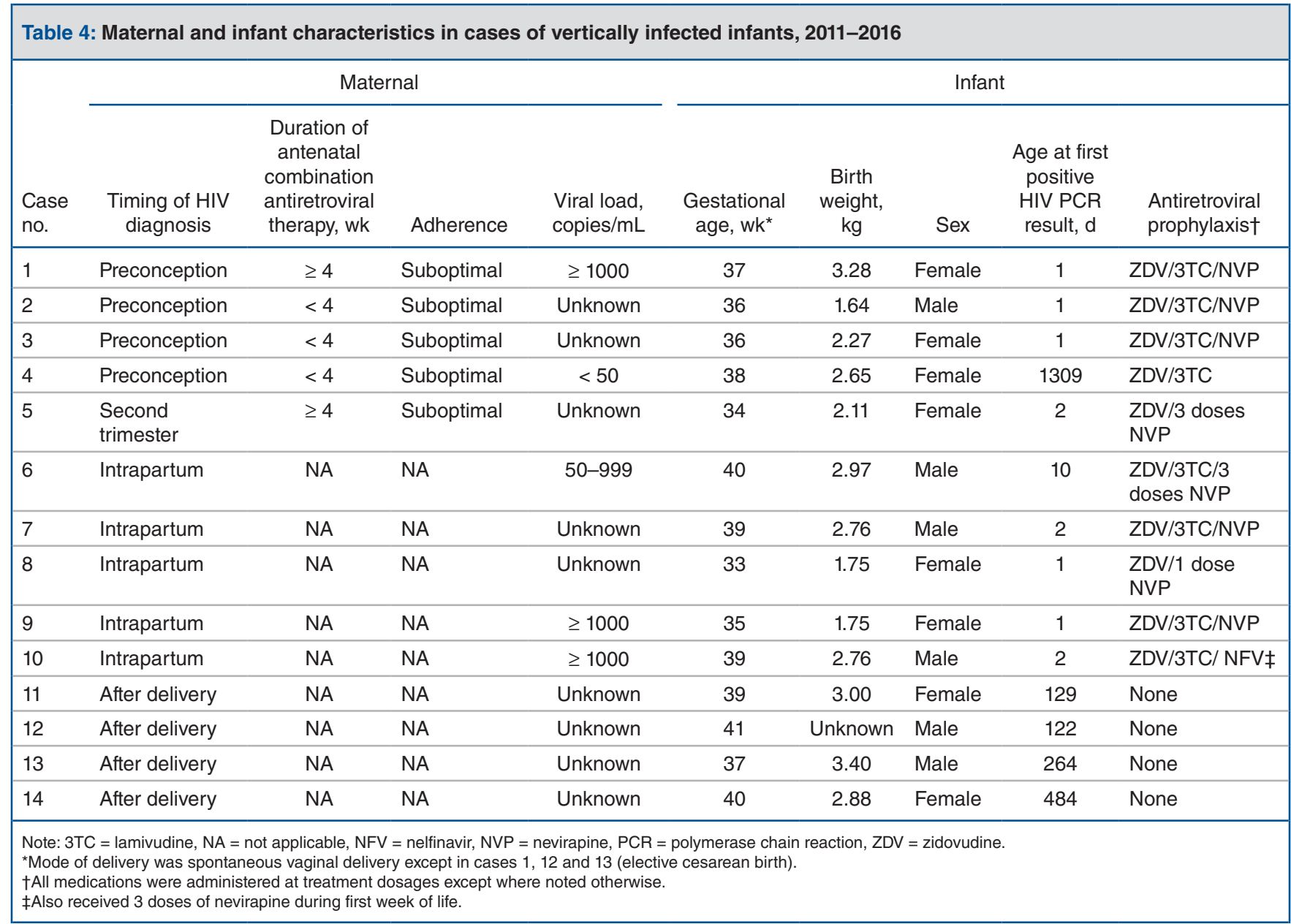

\section{Limitations}

A limitation of the CPHSP database is that it does not capture pregnant women with HIV infection whose status is unknown because they did not access antenatal care, declined HIV testing or seroconverted in pregnancy, after testing. In addition, there may be HIV-infected children who are not yet identified because the infection remains undiagnosed in them and their mothers. It is also possible that a small proportion of mother-infant pairs were missed because they received their care at non-CPHSP sites. However, given the provincial referral systems in place, we believe that there are few mother-infant pairs who are not captured in this surveillance system. The usual limitations of retrospective data collection apply, although their impact was tempered by our ability to obtain missing data in the process of routine infant follow-up. Incomplete data on maternal antiretroviral therapy and final infant HIV status were uncommon (1.6\% of cases) and were therefore unlikely to have affected key study findings.

\section{Conclusion}

Although there has been a steady decline in the rate of vertical HIV transmission in Canada, infant infections continue to occur, primarily as a result of incomplete implementation of known, evidence-based interventions. A major gap is the substantial number of women who do not receive antenatal combination antiretroviral therapy or are not started on such therapy until late in their pregnancy. Efforts to improve woman-centred timely access to care, HIV screening and treatment for all women, combined with enhanced resources targeting populations at increased risk for HIV infection, will be needed if vertical HIV transmission is to be eliminated in Canada.

\section{References}

1. Warszawski J, Tubiana R, Le Chenadec J, et al.; ANRS French Perinatal Cohort. Mother-to-child HIV transmission despite antiretroviral therapy in the ANRS French Perinatal Cohort. AIDS 2008;22:289-99.

2. Townsend CL, Byrne L, Cortina-Borja M, et al. Earlier initiation of ART and further decline in mother-to-child HIV transmission rates, 2000-2011. AIDS 2014;28:1049-57.

3. Whitmore SK, Taylor AW, Espinoza L, et al. Correlates of mother-to-child transmission of HIV in the United States and Puerto Rico. Pediatrics 2012;129: e74-81.

4. Forbes JC, Alimenti AM, Singer J, et al.; Canadian Pediatric AIDS Research Group (CPARG). A national review of vertical HIV transmission. AIDS 2012; 26:757-63.

5. Mandelbrot L, Tubiana R, Le Chenadec J, et al.; ANRS-EPF Study Group. No perinatal HIV-1 transmission from women with effective antiretroviral therapy starting before conception. Clin Infect Dis 2015;61:1715-25.

6. Scott GB, Brogly SB, Muenz D, et al.; International Maternal Pediatric Adolescent AIDS Clinical Trials Group (IMPAACT) P1025 Study Team. Missed opportunities for prevention of mother-to-child transmission of human immunodeficiency virus. Obstet Gynecol 2017;129:621-8.

7. European Collaborative Study in EuroCoord; Bailey H, Townsend C, Cortina-Borja $M$, et al. Insufficient antiretroviral therapy in pregnancy: missed opportunities for prevention of mother-to-child transmission of HIV in Europe. Antivir Ther 2011;16:895-903. 
8. Taylor AW, Nesheim SR, Zhang X, et al. Estimated perinatal HIV infection among infants born in the United States, 2002-2013. 7AMA Pediatr 2017;171: 435-42.

9. Trepka MJ, Mukherjee S, Beck-Sagué C, et al. Missed opportunities for preventing perinatal transmission of human immunodeficiency virus, Florida, 2007-2014. South Med 7 2017;110:116-28.

10. Read JS, Cohen RA, Hance LF, et al.; NISDI Perinatal/LILAC Study Group. Missed opportunities for prevention of mother-to-child transmission of HIV-1 in the NISDI Perinatal and LILAC cohorts. Int 7 Gynaecol Obstet 2012;119:70-5.

11. Prieto LM, González-Tomé MI, Muñoz E, et al. Low rates of mother-to-child transmission of HIV-1 and risk factors for infection in Spain: 2000-2007. Pediatr Infect Dis 7 2012;31:1053-8.

12. Money D, Tulloch K, Boucoiran I, et al.; Infectious Diseases Committee; special contributors. Guidelines for the care of pregnant women living with HIV and interventions to reduce perinatal transmission: executive summary. 7 Obstet Gynaecol Can 2014;36:721-34.

13. Bitnun A, Brophy J, Samson L, et al. Prevention of vertical HIV transmission and management of the HIV-exposed infant in Canada in 2014. Can 7 Infect Dis Med Microbiol 2014;25:75-7.

14. Camacho-Gonzalez AF, Kingbo MH, Boylan A, et al. Missed opportunities for prevention of mother-to-child transmission in the United States. AIDS 2015; 29:1511-5.

15. Peters V, Liu KL, Dominguez K, et al. Missed opportunities for perinatal HIV prevention among HIV-exposed infants born 1996-2000, Pediatric Spectrum of HIV Disease cohort. Pediatrics 2003;111:1186-91.

16. Whitmore SK, Patel-Larson A, Espinoza L, et al. Missed opportunities to prevent perinatal human immunodeficiency virus transmission in 15 jurisdictions in the United States during 2005-2008. Women Health 2010;50:414-25.

17. Riddell CA, Hutcheon JA, Dahlgren LS. Differences in obstetric care among nulliparous First Nations and non-First Nations women in British Columbia, Canada. CMA7 2016;188:E36-43.

18. Esber A, Cohen S, Dempsey A, et al. Using systems of care and a public health approach to achieve zero perinatal HIV transmissions. FAMA Pediatr 2017;171: 421-2.

Affiliations: Department of Pediatrics (Bitnun), The Hospital for Sick Children, University of Toronto, Toronto, Ont.; Canadian Institutes of Health Research Canadian HIV Trials Network (Lee, Singer), Vancouver, BC; Department of Pediatrics (Brophy, Samson), Children's Hospital of Eastern Ontario, University of Ottawa, Ottawa, Ont.; Department of Pediatrics (Kakkar), Centre hospitalier universitaire Sainte-Justine, University of Montreal, Montréal, Que.; Department of Pediatrics (Vaudry), Stollery Children's Hospital, University of Alberta, Edmonton, Alta.; Department of Pediatrics (Tan), Royal University Hospital, University of Saskatchewan, Saskatoon, Sask.; Department of Obstetrics \& Gynecology (Money), BC Women's Hospital and Health Centre; School of Population and Public Health (Singer); Oak Tree Clinic (Money, Sauvé,
Alimenti), BC Women's Hospital and Health Centre, University of British Columbia; Department of Pediatrics, University of British Columbia, Vancouver, BC (Sauvé, Alimenti)

Contributors: Terry Lee performed, and Joel Singer contributed to, the data analysis. Ari Bitnun drafted the manuscript, and Terry Lee, Jason Brophy, Lindy Samson, Fatima Kakkar, Wendy Vaudry, Ben Tan, Deborah Money, Joel Singer, Laura Sauvé and Ariane Alimenti revised the manuscript critically for important intellectual content. All of the authors contributed equally to the conceptualization and design of the study and data interpretation, gave final approval of the version to be published and agreed to be accountable for all aspects of the work.

Funding: No specific funding was secured for this study. The Canadian Perinatal HIV Surveillance Program is funded by the HIV/AIDS Surveillance Section, Surveillance and Risk Assessment Division, Public Health Agency of Canada. The CIHR Canadian HIV Trials Network provides data management and statistical support for the Canadian Perinatal HIV Surveillance Program.

Meetings at which the data were presented in part: Data from the Canadian Perinatal HIV Surveillance Program are presented annually at the Canadian Conference on HIV/AIDS Research. Presentations with a specific focus on missed opportunities for prevention of vertical HIV transmission were given at the 24th Annual Canadian Conference on HIV/AIDS Research, Apr. 30-May 3, 2015, Toronto (lecture) and the International AIDS Society meeting, July 19-22, 2015, Vancouver (poster).

Acknowledgements: The authors acknowledge Susan King (deceased), Stanley E. Read, Dorothy Moore, Normand Lapointe and John Forbes for their foresight in establishing the Canadian Pediatric \& Perinatal Research Group as well as the Canadian Perinatal HIV Surveillance Program in the early 1990s, without which this research would not have been possible. The authors thank all the site investigators at the participating centres for contributing data annually: Bob Bortulussi, Francois Boucher, Isabelle Boucoiran, Natalie Bridger, Jared Bullard, Jeff Cohen, Rick Cooper, Michele Ellis, Scott Halperin, Brendan Hanley, Taj Jadavji, Chris Karatzios, Valerie Lamarre, Kirk Liefso, Athena McConnell, Heather Onyett, Joan Robinson, Roger Sandre, Sandi Seigel, Michael Silverman, Alex Wong and Michael Young.

Supplemental information: For reviewer comments and the original submission of this manuscript, please see www.cmajopen.ca/content/6/2/ E202/suppl/DC1. 